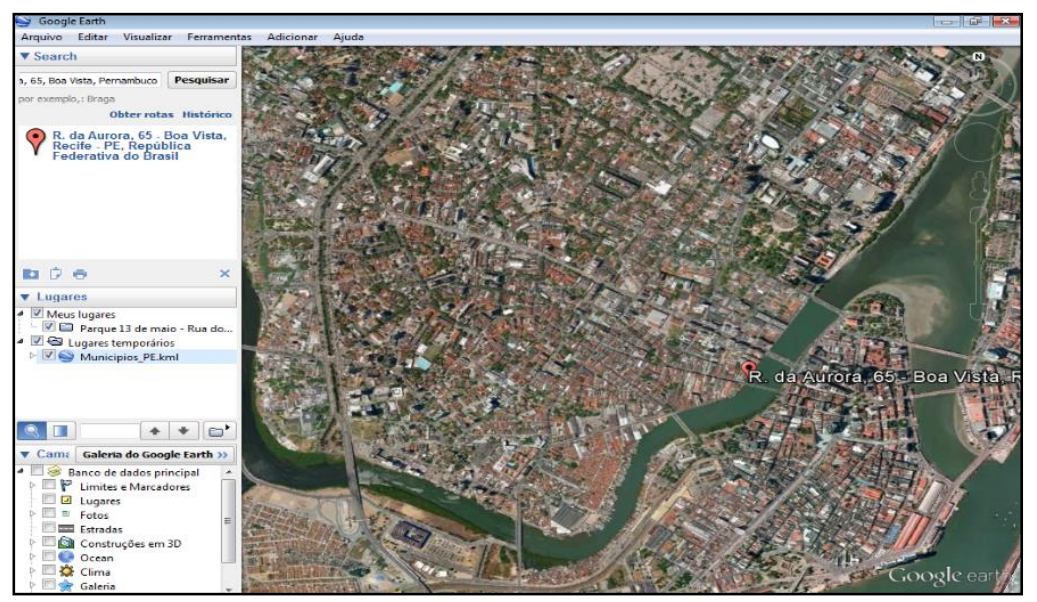

\title{
Buscando alternativas cartográficas: uma metodologia de subversão do sistema de informação geográfica
}

Seeking cartographic alternatives:

a methodology of subversion of the geographic information system

Cristiano Nunes Alves ${ }^{1}$

Resumo: Parte da construção de uma geografia renovada, amparada numa metodologia de pesquisa maleável, indaga sobre as possibilidades de subverter as funções técnicas do sistema de informação geográfica (SIG), utilizando-se de suas bases cartográficas, todavia, buscando uma produção alternativa ao sugestionado por meio de softwares de mapeamento. Para tanto, a proposta metodológica aqui apresentada, conduz a uma produção cartográfica subsidiada por programas gratuitamente disponíveis e de fácil manipulação, tais quais: Google Earth, editores de slides e editores de figuras. Procura-se, desse modo, conferir autonomia a geógrafos e demais pesquisadores, buscando contribuir para a discussão acerca da produção de cartografias mais flexíveis, menos ancoradas nas certezas que apenas o espaço euclidiano pode abrigar.

Palavras-chave: Meio-técnico-científico-informacional; Cartografia; Metodologia alternativa; Sistema de informação geográfica.

Abstract: Part of building a renewed geography, supported in a flexible methodology research, we ask for possibilities to subvert the technical functions of geographic information system (GIS), using their cartographic databases, although, looking for an alternative way to the cartographic production that is usually induced by the standard of mapping software's. Due this, the methodology introduced in this article comes to subsidize a cartographic production by the use of programs that have free access and are easy to handle, as such: Google Earth, editor of figures and editor of slides. Therewith we intend empower geographers and other researchers expecting that this proposal contribute to the discussion about producing a flexible cartography, less rooted in the certainty that only the Euclidean space can shelter.

Keywords: Medium-technical-scientific-informational; Cartography; Alternative methodology; Geographic information system.

\footnotetext{
${ }^{1}$ Doutor em Geografia, pós-doutorando em Geografia. Faculdade de Filosofia Letras e Ciências Humanas, Universidade de São Paulo. Endereço residencial: Rua Jaú, n ${ }^{\circ}$ 460, Cidade Nova II, Santa Bárbara D’Oeste - SP, CEP 13454-074 E-mail: cris7cris7@ yahoo.com.br
} 


\section{Introdução}

A construção de uma geografia renovada que possa dar conta da lancinante dinâmica socioterritorial contemporânea implica a um só tempo no desenvolvimento de um vigoroso sistema de conceitos e de uma metodologia de pesquisa maleável. Faz-se necessário, nas trilhas dessa geografia heroica (DARDEL, 2011 [1952]), assumir os riscos que apenas as novas propostas trazem, única maneira de responder às demandas dos lugares e de seus sujeitos.

Nessa via, indaga-se sobre as possibilidades de subverter as funções técnicas do sistema de informação geográfica (SIG), utilizando-se de suas bases cartográficas, todavia, buscando uma produção alternativa ao sugestionado por meio de softwares de mapeamento. Procura-se, desse modo, conferir autonomia a geógrafos e demais pesquisadores no que se refere à criação de mapas, fomentando, assim, o desenvolvimento de novas possibilidades para a representação cartográfica de fenômenos socioespaciais e a discussão sobre alternativas para a cartografia contemporânea.

Para tanto, apresenta-se a partir deste trabalho, proposta metodológica que subsidie a produção cartográfica por meio da utilização de programas disponíveis gratuitamente e de fácil manipulação. Um alvitre dinâmico, que longe de estar acabado, pretende mostrar-se como a entrada para práticas e pensamentos cartográficos instituintes.

Utilizando-se dos programas de computador Google Earth, editor de slides e editor de figuras, desenvolveu-se uma metodologia de trabalho cartográfico, aplicada em tese de doutoramento sobre a geografia da produção musical no Recife, estudo recentemente defendido na Universidade Estadual de Campinas (ALVES, 2014). Essa metodologia, alternativa aos modelos dos softwares de mapeamento, fora motivo de ricas discussões junto à banca examinadora, tendo sido utilizada em outros trabalhos na área de ciências humanas ${ }^{2}$, fato que impulsionou o esforço no sentido de divulgá-la para um público mais amplo.

Estrutura-se este artigo do seguinte modo: primeiramente discute-se a inserção do fazer cartográfico em um amplo e complexo processo de padronização em curso no período atual. Posteriormente, expõem-se os pormenores de uma metodologia

\footnotetext{
${ }^{2}$ A metodologia em questão fora aplicada ainda na cartografia presente em duas dissertações de mestrado em antropologia defendidas recentemente (2015) no Instituto de Filosofia e Ciências Humanas da Universidade Estadual de Campinas, por Catarina Casimiro Trindade e Ana Elisa Bersani.
} 
cartográfica pautada na subversão dos procedimentos difundidos por meio de um sistema de informação geográfica cristalizado em tempos recentes. Por fim, discutem-se as implicações teóricas, políticas e territoriais da busca por alternativas cartográficas.

Espera-se, com a presente proposta, contribuir para o debate acerca dos caminhos possíveis para que geógrafos e demais cientistas produzam cartografias mais flexíveis, menos amparadas nas certezas que apenas o espaço euclidiano pode abrigar.

\section{Delimitando uma problemática: cartografia, padronização e meio técnico- científico-informacional}

Traço cada vez mais marcante do período atual, a imposição de padrões, aspecto decisivo da criação cultural na sociedade moderna (GOLDMANN, 1972), permeia as mais diversas esferas da vida cotidiana. Esse processo uniformizante, um dos pilares da indústria cultural (ADORNO, 2004 [1947]), manifesta-se, entre outros, seja nos conteúdos impostos via produção fonográfica e via radiodifusão (ALVES, 2008; LUCCA, 2001), seja na grande mídia, por meio dos procedimentos de tratamento e difusão de notícias (ABRAMO, 2003), atingindo igualmente a produção cartográfica.

Com o adensamento do período do meio técnico-científico-informacional (SANTOS, 1997), os métodos aplicados à cartografia, ancoraram-se e concentraram-se paulatinamente nos aparatos e procedimentos computacionais tributários do Sistema de Informação Geográfica (SIG). Nesse processo, a dose de arte, autonomia e peculiaridade que acompanhou a história da cartografia, apartou-se dessa parcela do pensamento e do fazer geográfico, responsável por produzir a representação gráfica dos fenômenos espaciais em suas inúmeras escalas e possibilidades.

Programas de computador (softwares) $)^{3}$ e prerrogativas do sensoriamento remoto, impostos por um seleto grupo de empresas de informação, passam a ser tratados como a quintessência do conhecimento geográfico, e pesquisadores - geógrafos ou não portadores da licença de utilização e detentores do treinamento necessário para operarem tais ferramentas, tornam-se os "seres iluminados", os únicos capazes de tornar realidade o fazer cartográfico.

Aspirando balizar a reflexão crítica sobre o espaço geográfico, também “cartografável” sob o prisma da resistência (CRAMPTON \& KRYGIER, 2006), capaz de deflagrar processos e fenômenos territoriais corriqueiramente ocultados, destaca-se a

\footnotetext{
${ }^{3}$ Entre os softwares de análise e representação espacial temos o Mapinfo, ArcGIS, GEOMEDIA, ISmart, Transcad, Mapwindow, SAGA GIS e Visual SIG.
} 
proposta de Ribeiro (2011) sobre a necessidade de uma “cartografia da ação". Segundo a autora supracitada, tratar-se-ia de uma geografização das práticas lugarizadas, que deixe falar os agentes periféricos, os que se utilizam da cidade como abrigo, vozes para quem o poder instalado parece estar surdo.

Ora, entende-se que a surdez para com agentes periféricos, suas aspirações e topologias, espraia-se além do conteúdo a ser cartografado e invade a forma como tais procedimentos de mapeamento são desenvolvidos e difundidos.

Nessa via, Fonseca (2004, p. 9) chama a atenção para a "inflexibilidade do espaço cartográfico" propondo a seguinte indagação: "haveria um desenvolvimento da cartografia em consonância com a renovação da geografia?”. Compartilha-se dessa inquietação e afirma-se que a um só tempo a reflexão, a temática e a produção cartográfica são enquadradas, impedindo a construção de métodos e metodologias alternativos ao pensamento obediente e racionalizante em voga no período atual, afastando boa parte dos geógrafos do fazer cartográfico.

Não por acaso, expressa-se aqui um anseio analítico por criar "outras" leituras e representações espaciais, para além do SIG, seus softwares e agentes instituídos.

\section{Apresentando a metodologia cartográfica (de subversão).}

A elaboração de mapas por meio da metodologia alternativa aqui proposta, divide-se basicamente em cinco etapas: 1) preparação da base cartográfica; 2) estabelecimento da escala; 3) estabelecimento de coordenadas; 4) construção da topologia; 5) formatação do mapa.

Para a preparação da base cartográfica, utiliza-se as imagens do programa Google Earth, o que não impede que a metodologia possa ser aplicada em outras bases ou então como modo de acrescentar informações a outros mapas. Na internet deve-se baixar um arquivo no formato " $\mathrm{Kmz}$ ", contendo a compartimentação territorial relativa à área a ser cartografada, seja ela distrital, municipal, estadual, nacional ou global (Figura 1).

\footnotetext{
${ }^{4}$ Trata-se de um arquivo KML principal, com zero ou mais arquivos de suporte compactados usando um utilitário ZIP.
} 


\section{Figura 1}

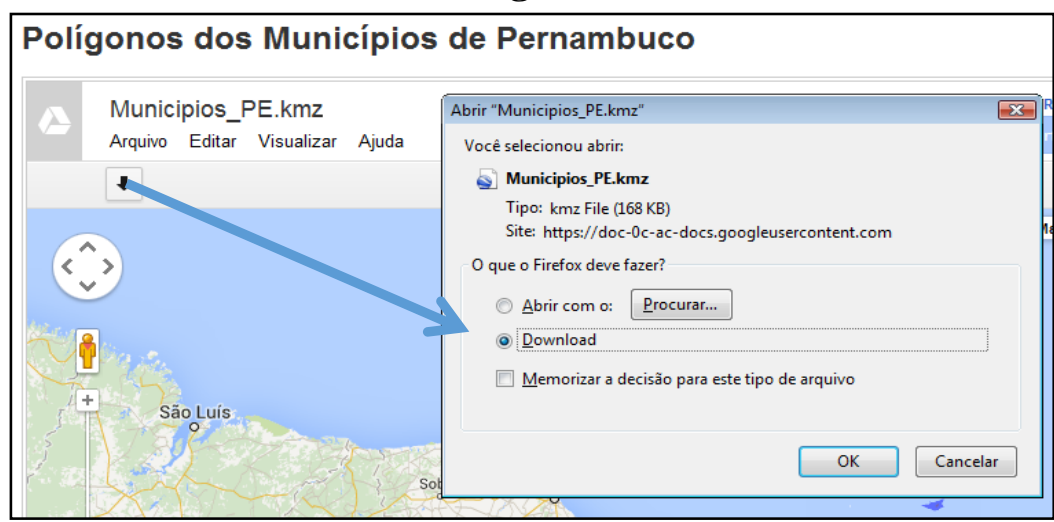

Elaboração própria, 2014.

Deve-se salvar no computador o arquivo Kmz e em seguida inseri-lo no Google Earth, acionando o ícone arquivo e solicitando a sua abertura (Figura 2). Automaticamente será lançado um foco na área compreendida pelo arquivo Kmz inserido. Adotou-se como exemplo a cidade do Recife, capital do Estado de Pernambuco (Figura 3).

Figura 2

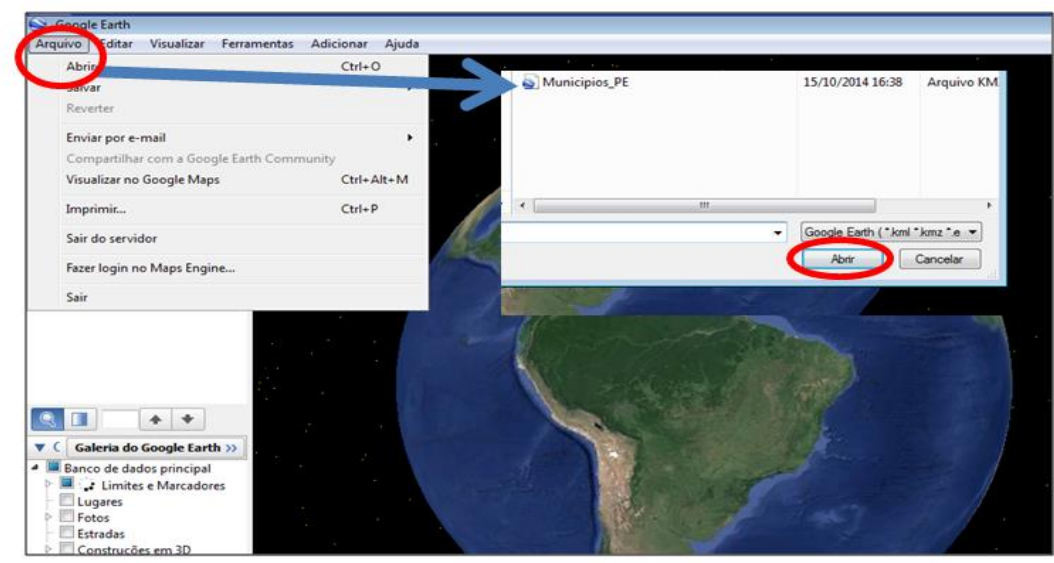

Elaboração própria, 2014.

\section{Figura 3}




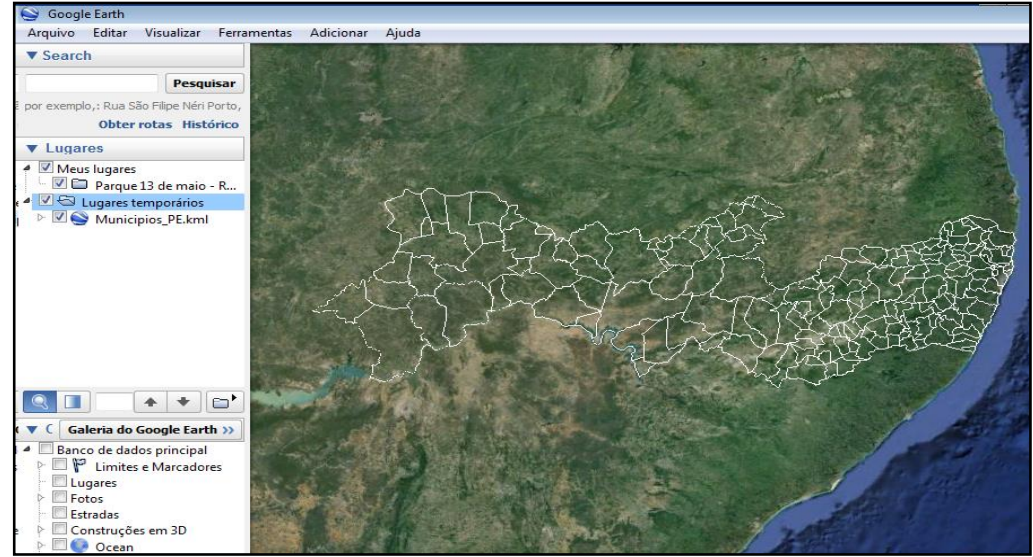

Elaboração própria, 2014.

Na tela inicial do Google Earth aciona-se o ícone visualizar e desabilita-se itens visuais que possam se sobrepor e/ou diminuir o campo de exibição da área a ser cartografada, tais quais: 1) barra de ferramentas; 2) barra lateral; 3) ferramenta de navegação (Figura 4).

\section{Figura 4}

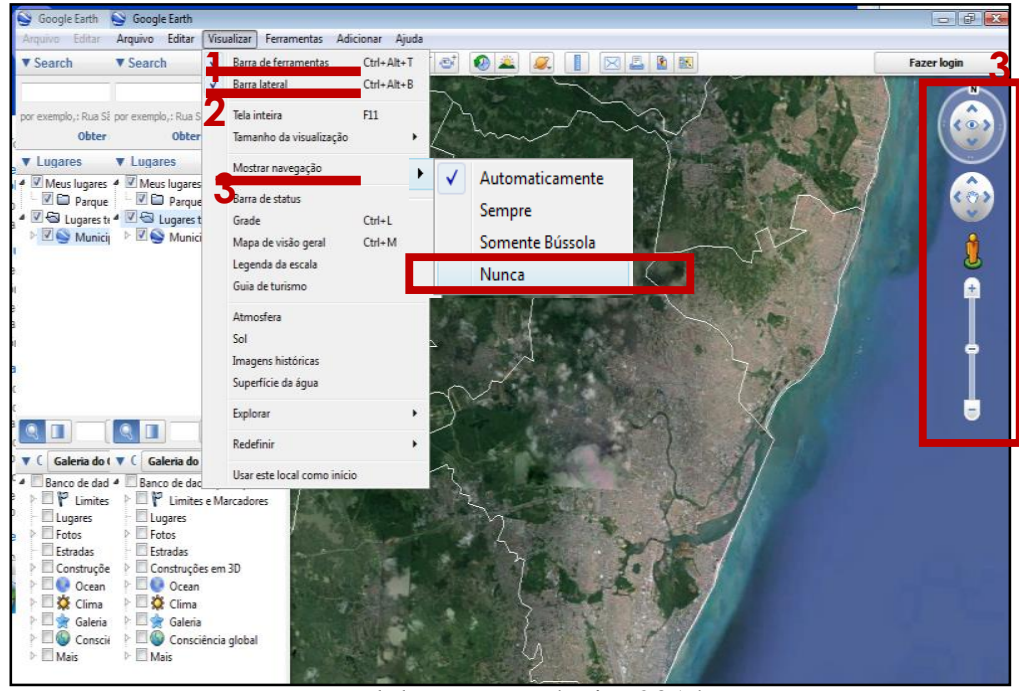

Elaboração própria, 2014.

No Google Earth a base cartográfica será exibida por toda a tela. No exemplo adotado, a cidade do Recife, cuja extensão se impõe no sentido norte-sul, ao girar a imagem no sentido horário a partir da barra de navegação, será obtida maior amplitude (Figura 5), procedimento importante, visto que a imagem será enviada ao editor de figuras por meio do comando "Print Screen".

\section{Figura 5}




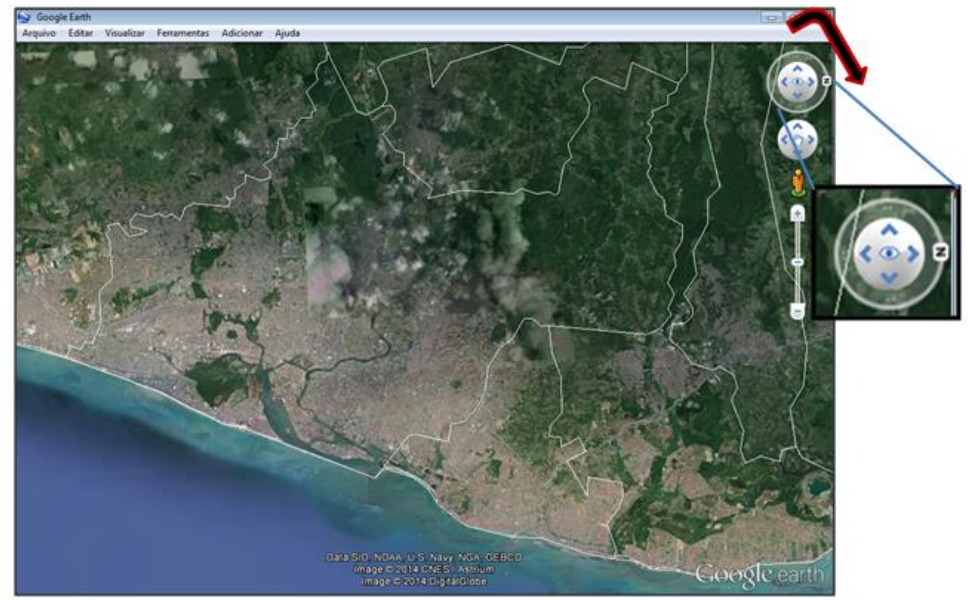

Elaboração própria, 2014.

$\mathrm{Na}$ tela inicial do editor de figuras (Figura 6), seleciona-se a área correspondente à base cartográfica a ser utilizada. Envia-se a imagem ao editor de slides (Figura 7) por meio dos comandos "copiar" e "colar". Gira-se a imagem utilizando-se do comando acionado via lado direito do mouse (Figura 8).

Figura 6

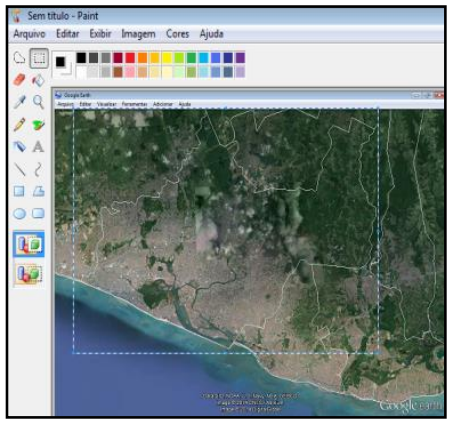

Figura 7

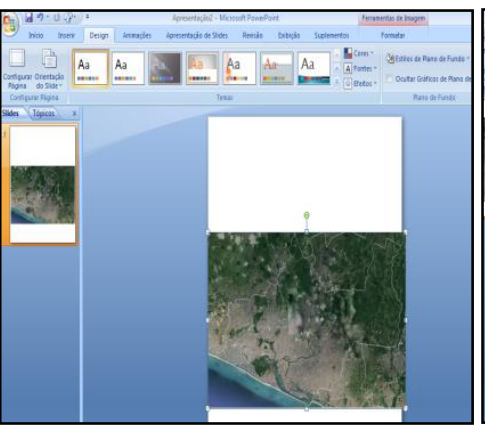

Elaboração própria, 2014.
Figura 8

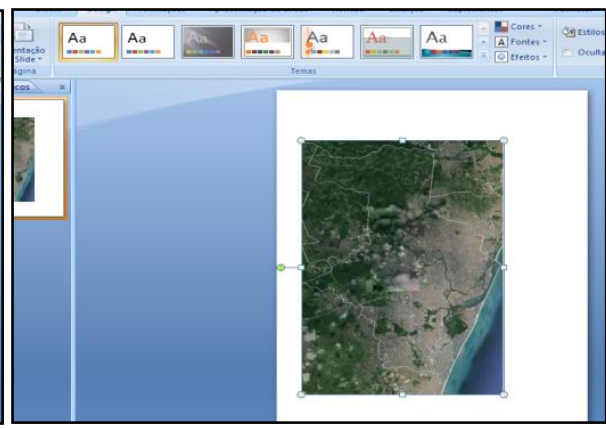

Uma vez preparada a base cartográfica, deve-se estabelecer a escala de trabalho do mapa. Aciona-se no Google Earth (Figura 9), o ícone ferramentas (1) e escolhe-se a opção régua (2). Utilizando-se a régua em linha, verifica-se a distância entre dois pontos conhecidos (3). No exemplo em questão, parte-se do limite oeste da divisa entre Recife e Olinda até o limite oeste da Ilha de Santo Antônio, distância de 3.000 metros.

\section{Figura 9}




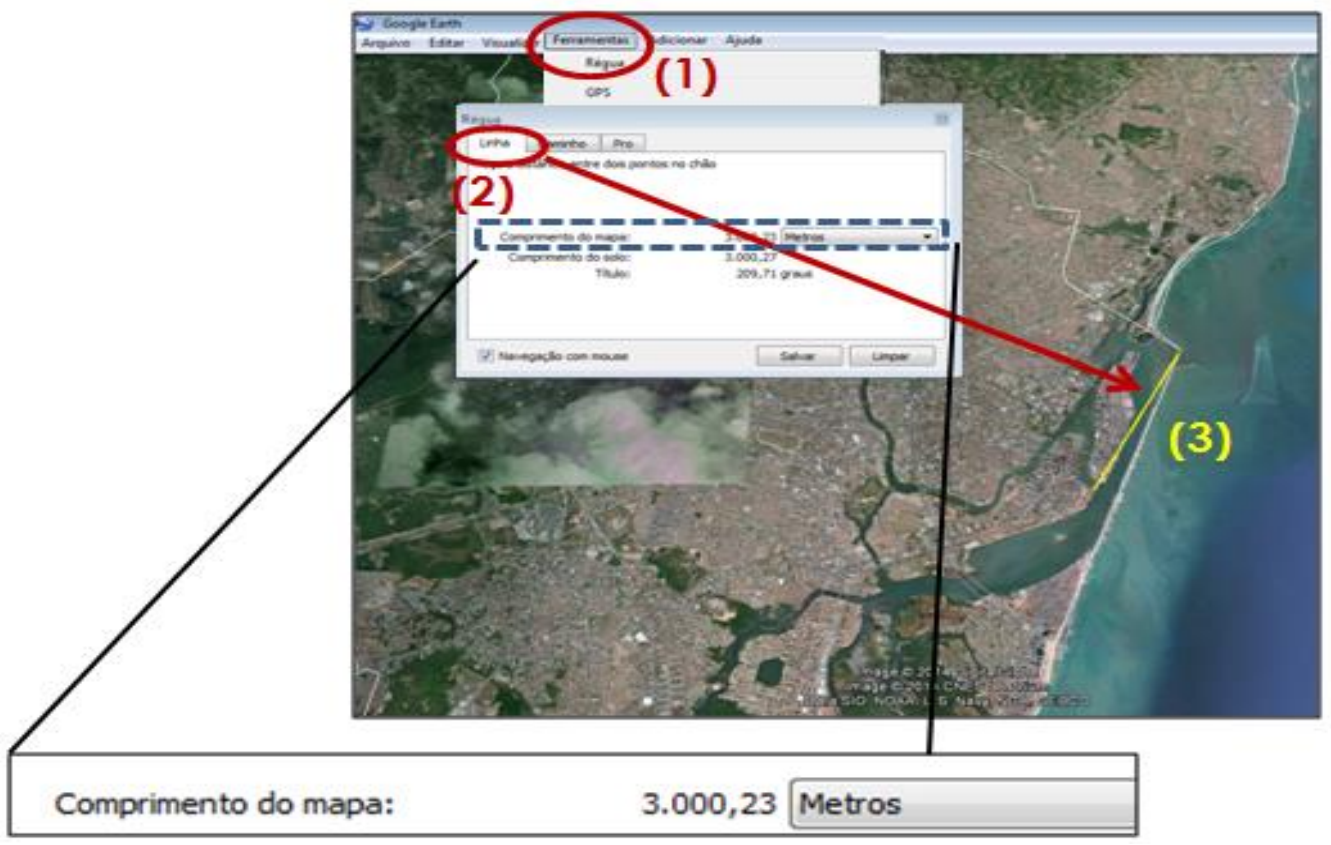

Elaboração própria, 2014

A escala pode ser obtida de modo analógico, por meio de regra de três. De acordo com o exemplo adotado (Figura 10), três quilômetros na realidade correspondem a dois centímetros na representação, logo, cada centímetro na representação corresponde a 1500 metros na realidade. Uma vez definida, a escala gráfica será inserida na figura, procedimento a ser esmiuçado mais à frente no texto, ao abordar-se a formatação do mapa.

Figura 10

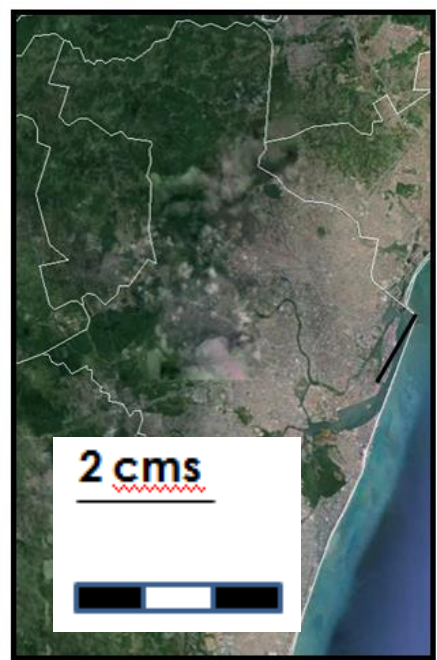

Elaboração própria, 2014.

A metodologia alternativa propicia ainda o estabelecimento de coordenadas. Para tanto, no Google Earth aciona-se o ícone visualizar, que disponibiliza os itens 
barra de status (1) e grade (2), estes podem ser utilizados para a inserção de coordenadas na base cartográfica inserida previamente no editor de slides (Figura 11).

Figura 11

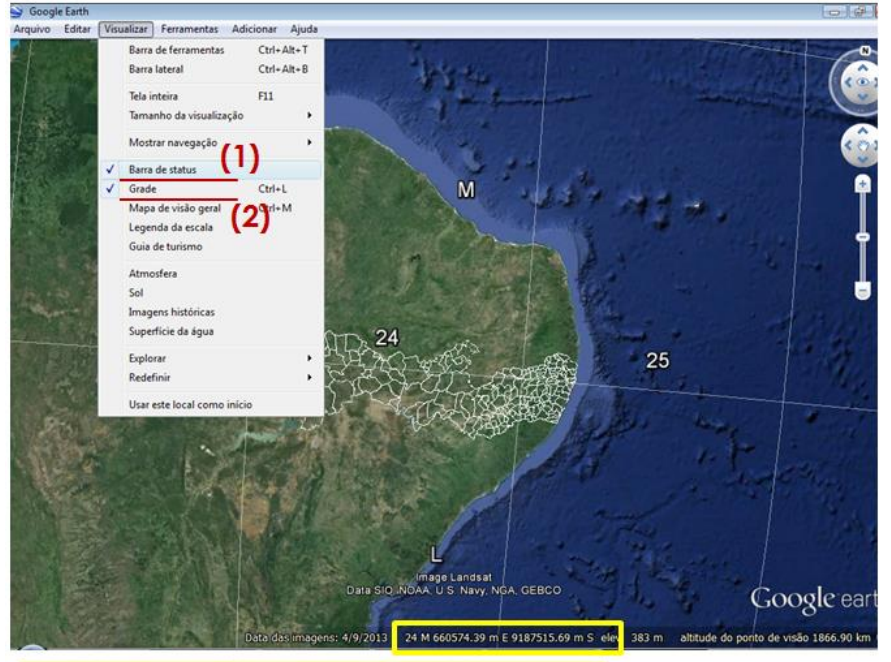

24 M 660574.39 m E 9187515.69 m S elev 383 m

Elaboração própria, 2014.

Estabelecidas as referências da base cartográfica, inicia-se a construção da topologia de acordo com as variáveis em questão no mapa. Desse modo, localiza-se no Google Earth a variável a ser cartografada, seja por meio da pesquisa de endereço ou lançando mão do conhecimento da posição aproximada (Figura 12). Em seguida, iniciase a inserção de figuras de representação de modo analógico, utilizando-se, ao mesmo tempo, da imagem do Google Earth e da base cartográfica inserida no editor de slides.

\section{Figura 12}

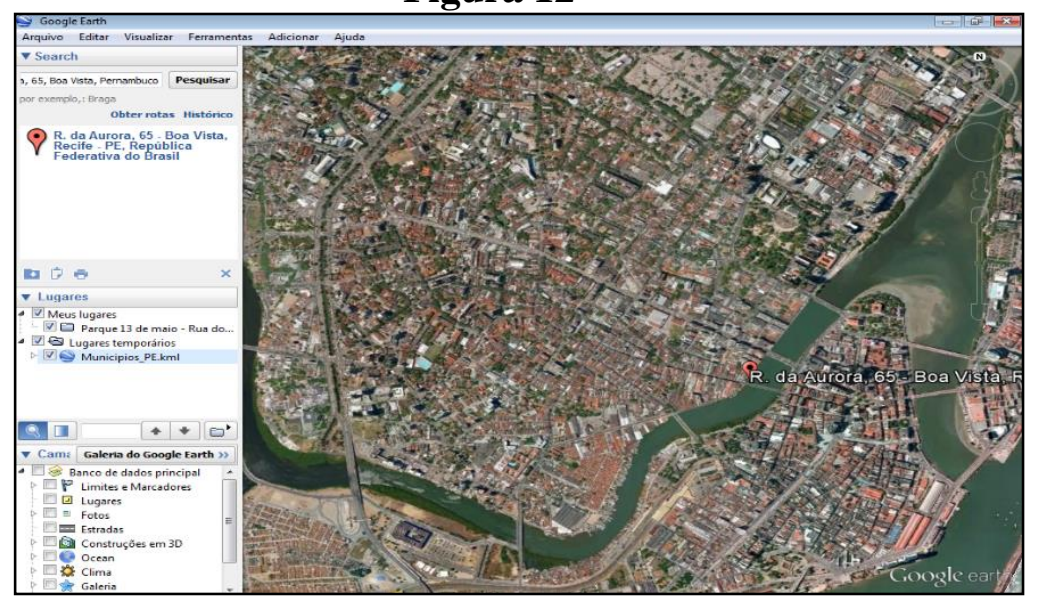

Elaboração própria, 2014.

A última etapa da presente metodologia, que ocorre no editor de slides, é a formatação do mapa. Recomenda-se iniciar o processo pela base cartográfica, inserindo 
os efeitos necessários, por meio do ícone formatar imagem (Figura 13), acionado com o lado direito do mouse, possibilitando ajustes no preenchimento da base cartográfica, em sua moldura (Figura 14), entre outros.

Figura 13

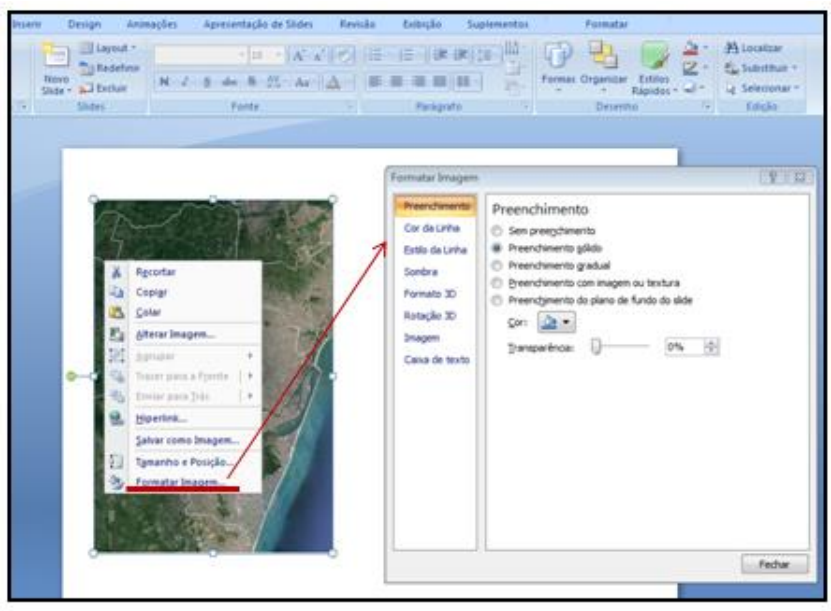

Figura 14

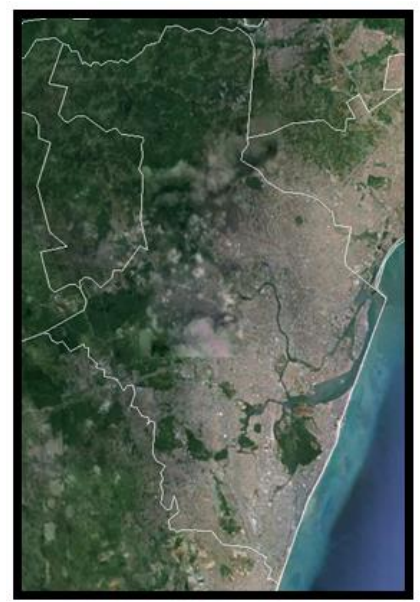

O ícone formas (Figura 15) do editor de slides dispõe de considerável conjunto de figuras, que aliadas à ferramenta formatar forma (Figura 16) exposta anteriormente, conferem larga margem de manobra da elaboração do mapa. Trata-se de um processo livre, oportunidade para que a criatividade do pesquisador seja dinamizada, por meio de combinações, trato com texturas e demais recursos visuais.

Figura 15

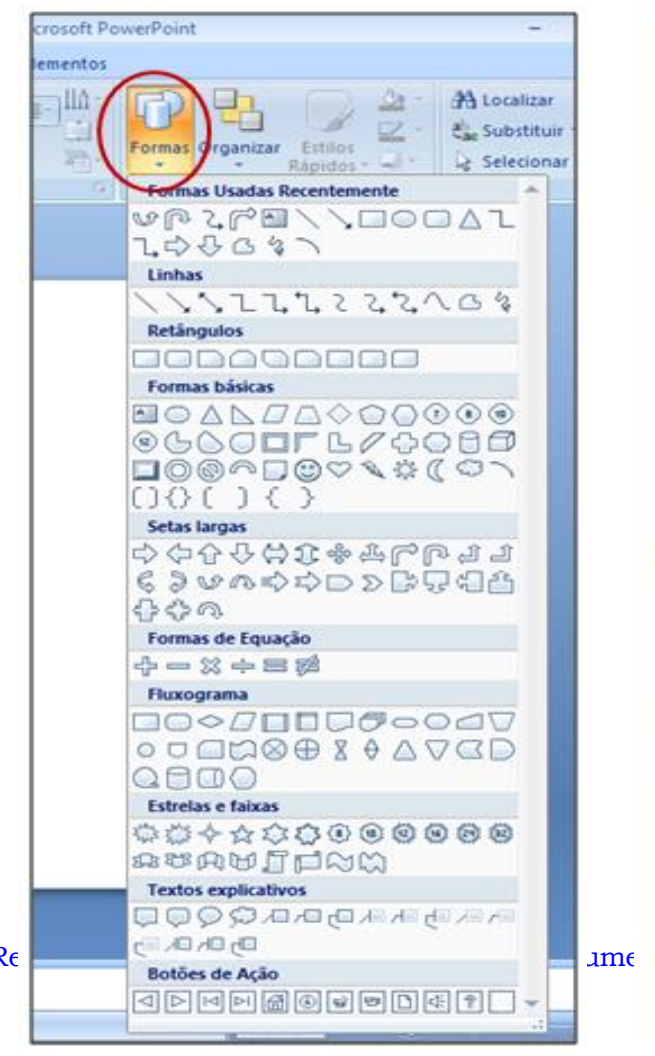

Figura 16

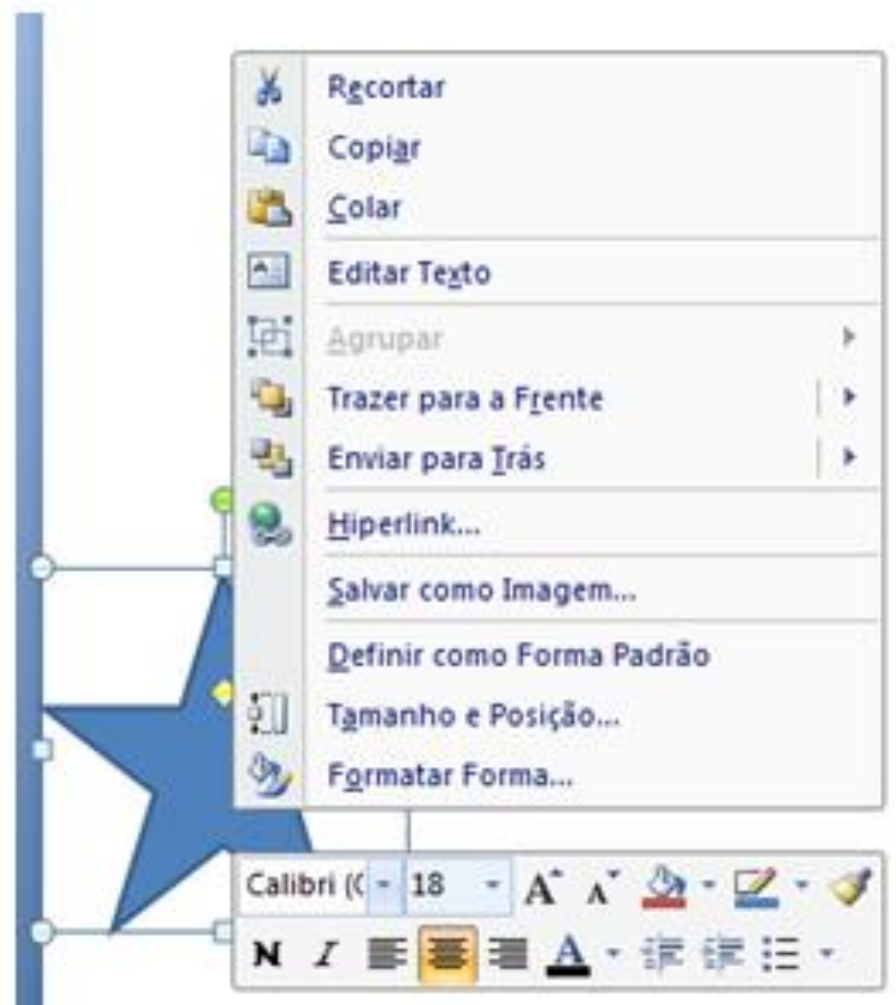


As combinações e gradações podem ser desenvolvidas, utilizando-se de ferramentas como tamanho e posição (Figura 17), ou definir forma, que, entre outras, possibilitam ajustar a transparência da forma em questão (Figura 18), interessante recurso para sobrepor informações e/ou destacar áreas do mapa

Figura 17

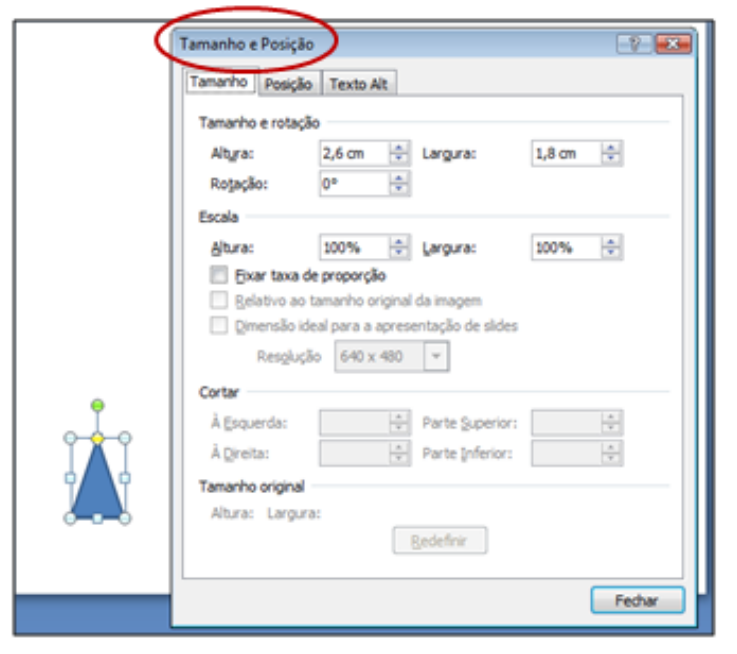

Figura 18

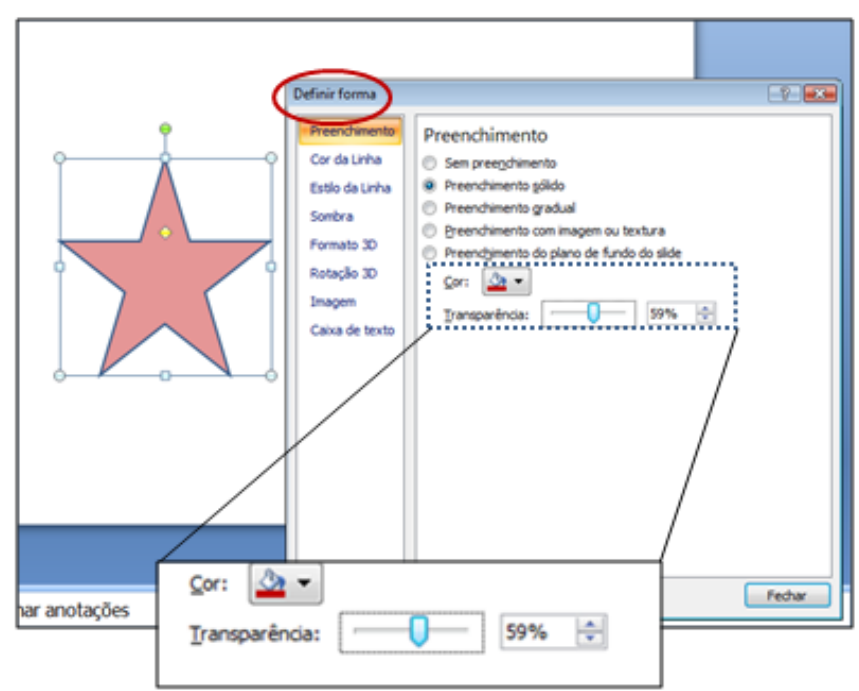

Elaboração própria, 2014.

Itens como a moldura e a legenda do mapa podem ser elaborados tanto por meio da formatação de uma caixa de texto (Figura 19), quanto pela inserção de uma forma sem preenchimento ou com um preenchimento em transparência (Figura 20). Outros efeitos podem ser aplicados utilizando-se das possibilidades do item ferramentas de desenho (Figura 21).

\section{Figura 19}




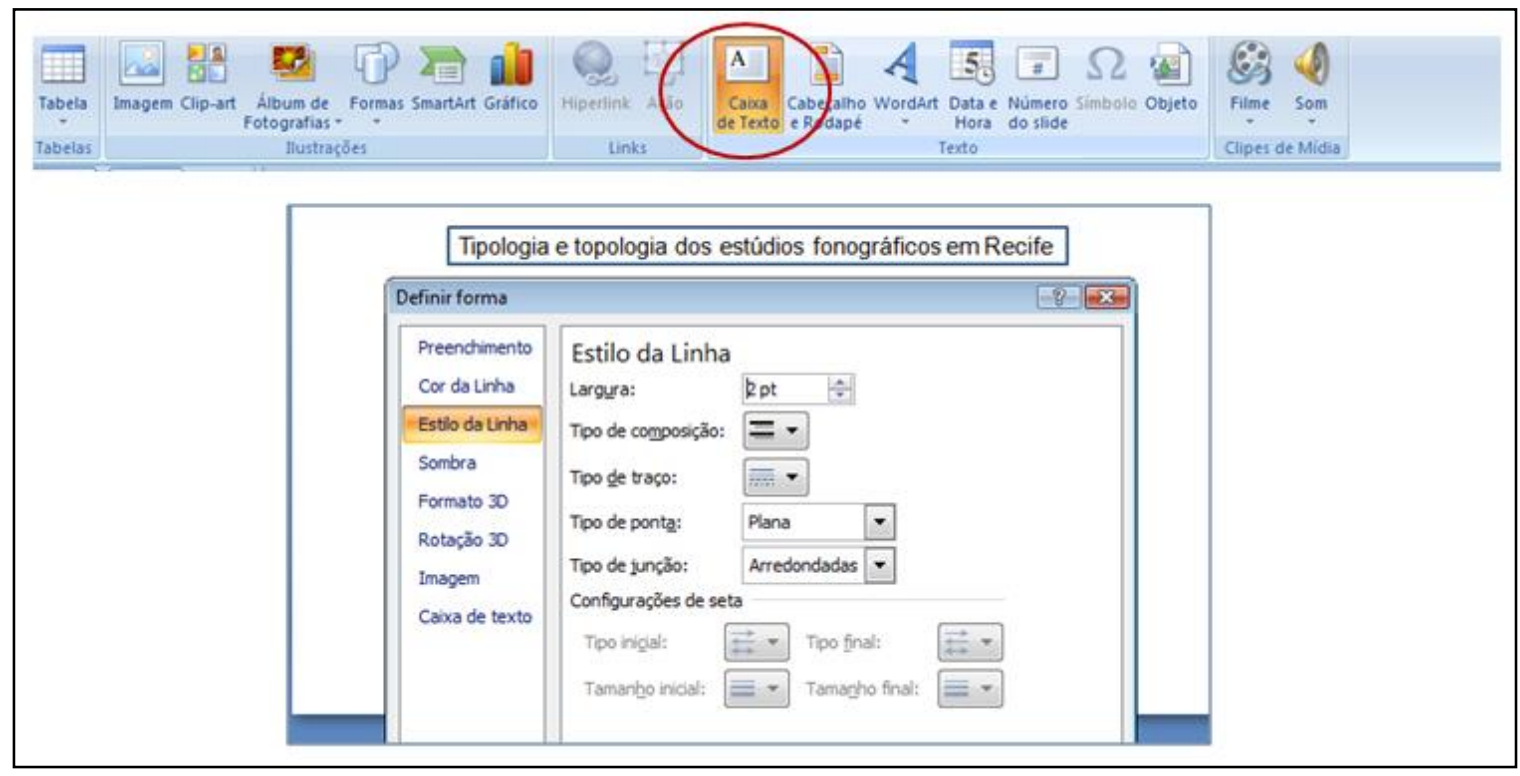

Elaboração própria, 2014.

Figura 20

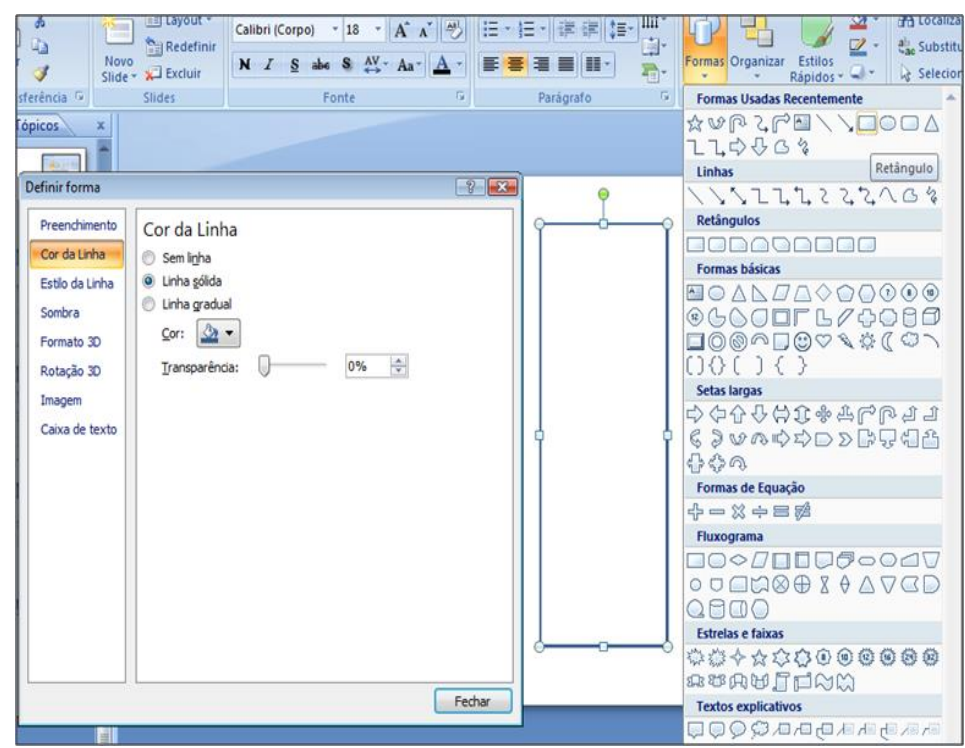

Figura 21

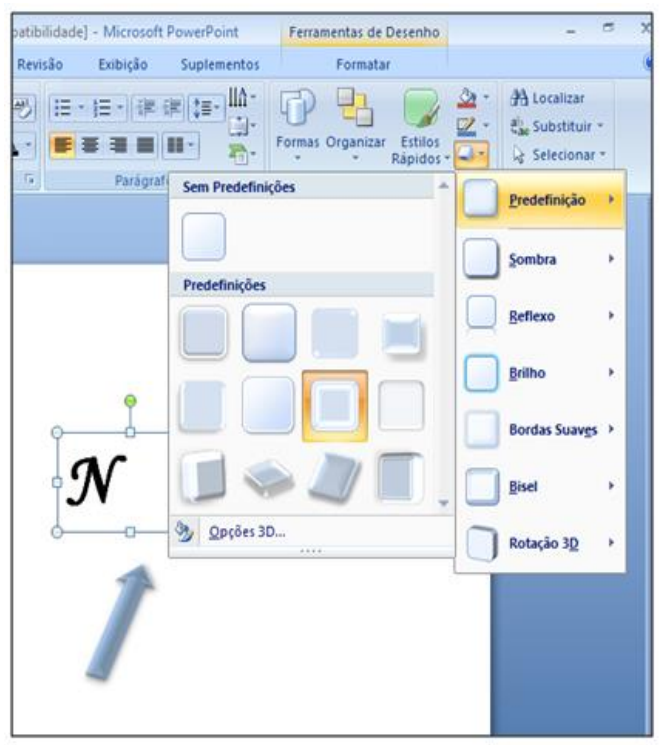

Elaboração própria, 2014.

Destaca-se, ainda, que variáveis agrupadas em distintos mapas podem ser entrecruzadas. Para tal tarefa, basta, no editor de slides, utilizar-se os comandos “copiar" e "colar": 1) agrupando os dados; e 2) observando as equivalências de escalas entre os mapas (Figura 22). No exemplo abaixo, apresenta-se a sobreposição das 
informações relativas à topologia de duas cenas musicais abrigadas no Recife entre os anos 1980 e 1990: a Cena Manguebit - pautada na fusão sonora entre gêneros de música elétrica e ritmos negros como o maracatu - e a Cena Recife - composta por bandas oriundas dos subúrbios da metrópole pernambucana (Figuras 23 e 24).

Figura 22
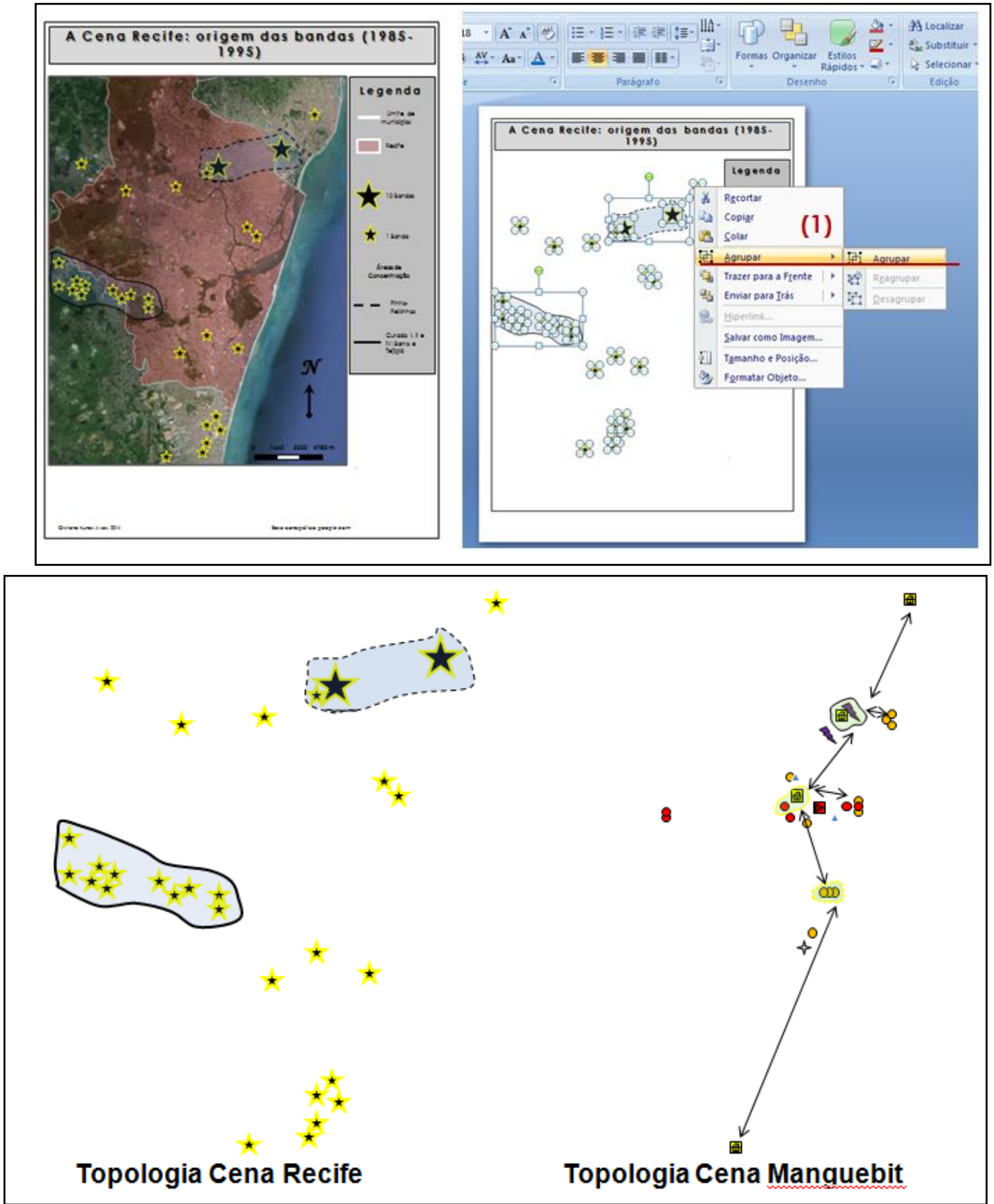

Elaboração própria, 2014.

Figura 24

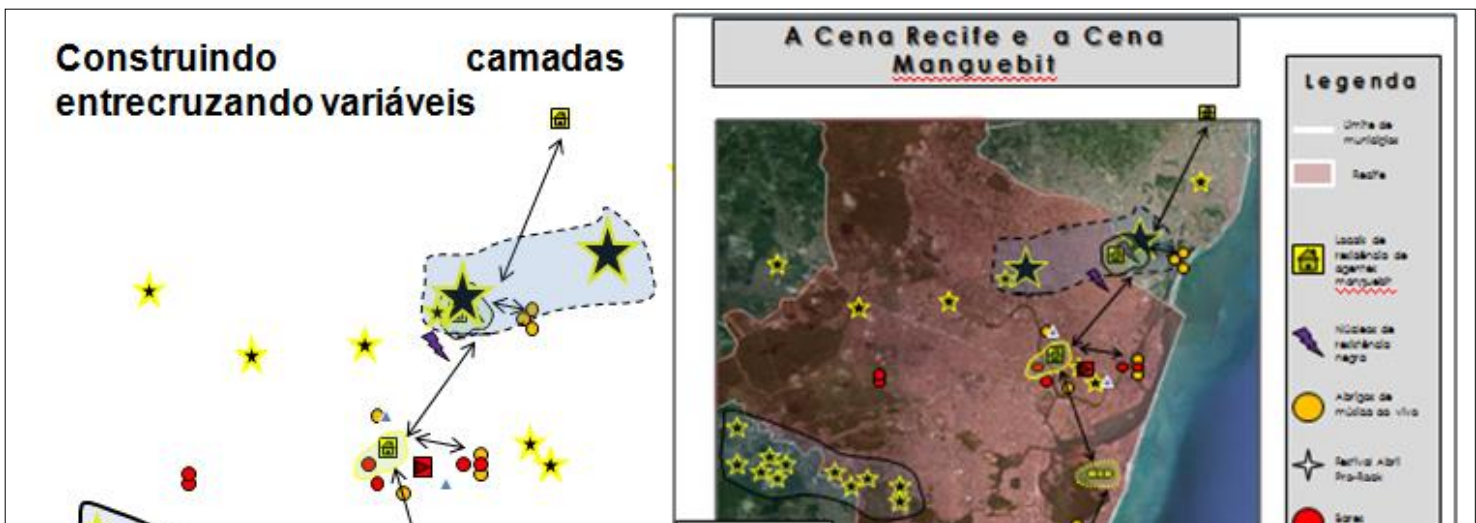


Elaboração própria, 2014.

Por fim, apresenta-se o mapa dos bens e serviços musicais abrigados na Região do Recife (Figura 25), no qual cartografou-se escolas de música, oficinas de lutieria, empresas duplicadoras de mídias, lojas de discos e lojas de instrumentos musicais.

\section{Figura 25}

\section{O Circuito Sonoro: o comércio de bens e serviços musicais na Região do Recife(2014)}

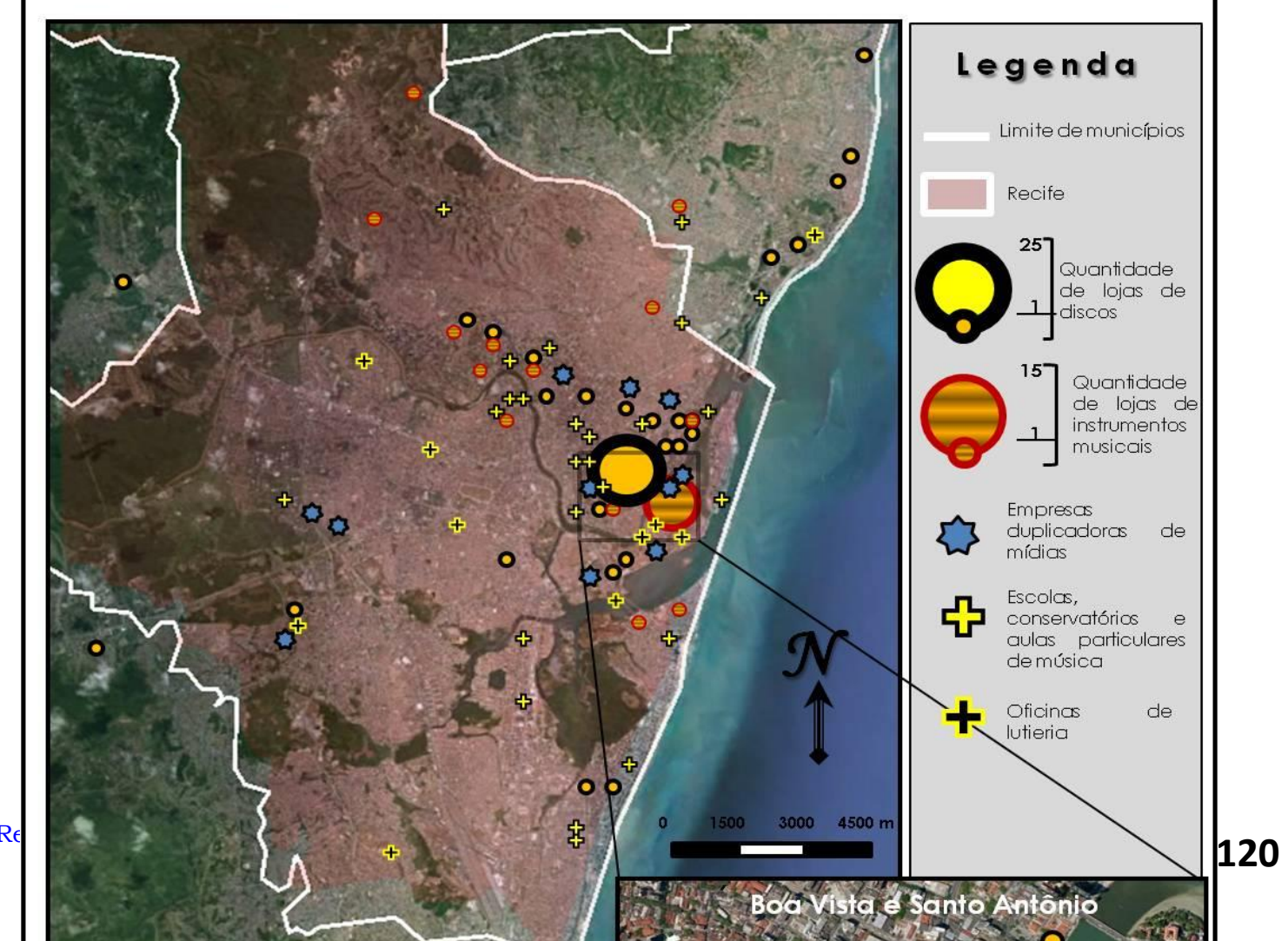




\section{Alternativas cartográficas: técnica, informação e subversão em movimento}

A técnica da informação característica do meio contemporâneo traz consigo inúmeros aspectos correlatos, tais como a informatização, a creditização, a instantaneidade ou a importância do controle informacional (SANTOS, 1997), expressa, entre outros, na rigidez aplicada à cartografia.

Daí, em um território assolado por pensamentos e atividades obedientes a uma racionalidade instrumental à manutenção de um desigual estado de coisas, a subversão da função dos objetos e sistemas técnicos pareça ser um dado que nos impõe acuidade em sua análise.

Nossa reflexão sobre as alternativas cartográficas se alicerça na categoria território usado, proposta por Santos \& Silveira (2001, p. 20), sinônimo de espaço geográfico, entretanto, apontando para "a necessidade de um esforço destinado a analisar sistematicamente a constituição do território".

Tarefa do geógrafo, a análise pormenorizada do espaço geográfico requer o desenvolvimento de ferramentas investigativas que deem conta da realidade de nossa formação socioespacial (SANTOS, 1977), terceiro mundista, prenhe de precariedade, mas também de riqueza criativa.

Nesse sentido, a metodologia de subversão do SIG mostra como, combinados e reordenados por usos dissonantes, objetos e sistemas técnicos, alinhados a uma técnica ressignificada, podem originar novas possibilidades políticas para o território usado. 
Ora, ensina-nos Sánchez (1992, p. 268), parte das inovações técnicas ao se tornarem uma realidade, podem se independentizar de seus produtores, permitindo que elas sejam "apropriadas por outros indivíduos" e "aplicadas por outras pessoas", enquanto Ortega y Gasset (1963, p. 55) destacam a solidariedade das técnicas ao mencionar a "facilidade com que um artefato ideado para servir uma determinada finalidade se desloca para outras utilizações".

Poderiam tais pressupostos nos auxiliar no estudo da subversão dos objetos e funções técnicas no caso da apropriação das novas tecnologias da informação por meio de metodologias cartográficas alternativas?

A esse termo, interessante entrada para discutir o modo de ação marginal nas cidades do terceiro mundo, lugares marcados pela desigualdade socioterritorial, Santos (1994) propõe a noção de "flexibilidade tropical”. Segundo o autor supracitado, o "meio ambiente construído", retrato da diversidade da urbe, expressão de distintas classes sociais, níveis de renda e modelos culturais; implica que, nos espaços opacos, abriguemse formas de fazer alternativas a uma racionalidade "triunfante", frutos da lida cotidiana com a situação de precariedade, tornando possível a sobrevivência e novos olhares sobre a realidade.

Por outro lado, elemento crucial à reflexão sobre as implicações políticoterritoriais da metodologia de subversão cartográfica, Ribeiro (1994, p. 154) destaca a possibilidade dos lugares e sujeitos em seus cotidianos melhor se articularem por meio da informação, na busca por usos do território mais igualitários: "Como transformar informação em comunicação socialmente útil? Como reconstruir caminhos que permitam a superação da face quase que exclusivamente mercantil da informação?”.

Contribuindo à discussão, inspirando-nos na busca por outros fazeres cartográficos, para além das certezas, Ribeiro (2005, p. 115) afirma que a análise social crítica "deverá incluir os lugares" e o respeito às diferenças culturais decorrentes da experiência cotidiana, indicativo da reciprocidade com relação às formas de resolver a vida:

Sem dúvida, a arte de 'resolver' a vida pode conter elementos da servidão humana que marcam a desigual sociedade brasileira. Porém, esta arte possivelmente contém elementos, mesmo que embrionários, da autonomia que constrói o lado libertário dos sujeitos sociais.

\footnotetext{
5 “...una vez desarrolladas, (...) se independizan de ellos, adquiriendo un caráter autônomo que permite ser apropiadas por otros indivíduos y ser aplicadas a su vez por otras personas...” (SÁNCHEZ, 1992, p. 268).
} 
Entendemos que a busca por alternativas na teoria e no fazer geográfico, aqui expressa na metodologia de subversão do SIG, requer o reconhecimento das mais diversas formas de resolver a vida, intrínsecas à nossa formação socioespacial. Procura-se, assim, erigir pontes entre a teoria e a concretude de objetos e ações, o empírico em suas contradições, possibilidades e lutas políticas (RIBEIRO, 2003), focando a análise do território visto como "um todo complexo onde se tece uma trama de relações complementares e conflitantes" (SANTOS et all, 2000, p. 3).

\section{Considerações finais}

Com a apresentação da metodologia de subversão do SIG, procura-se menos negar procedimentos cristalizados, do que se propor outros caminhos e meditações cartográficas.

Observou-se que, a partir do uso de programas de computador de fácil acesso e de simples manipulação, grande parte das temáticas abordadas na geografia e em outras ciências humanas podem ter a sua topologia revelada. Verificou-se, desse modo, a possibilidade de conferir maior autonomia a pesquisadores que necessitam representar espacialmente os fenômenos sob os quais se debruçam.

Longe de ser um alvitre fechado e estático, a metodologia de subversão cartográfica sinaliza para a abertura e a experimentação na medida em que sinaliza para um processo de trabalho que pode e deve ser alterado, revisto, ampliado e interrogado.

Trata-se, assim, de um procedimento em construção, em constante mudança, consoante com a própria dinâmica socioterritorial, fugaz e arredia em sua dialética. Espera-se que esta proposta não seja a única e que ela contribua para que cada vez mais o que é oferecido a nós, geógrafos, como verdade absoluta, seja questionado.

\section{Referências bibliográficas}

ABRAMO, Perseu. Padrões de manipulação na grande imprensa. São Paulo-SP: Editora Fundação Perseu Abramo, 2003.

ADORNO, Theodor W. Indústria cultural e sociedade. São Paulo: Paz e Terra, 2004 [1947].

ALVES, Cristiano Nunes. O circuito sonoro: radiodifusão FM e produção fonográfica em Campinas-SP. Dissertação (mestrado em geografia), Instituto de Geociências, Universidade Estadual de Campinas. Campinas, 2008. 
ALVES, Cristiano Nunes. Os circuitos e as cenas da música na cidade do Recife: o lugar e a errância sonora. Tese (Doutorado em Geografia), Instituto de Geociências, Universidade Estadual de Campinas. Campinas, 2014.

CRAMPTON, Jeremy W. \& KRYGIER, John. An Introduction to critical cartography. ACME: An International E-Journal for Critical Geographies, 4 (1), 11-33, 2006.

DARDEL, Eric. O homem e a terra: natureza da realidade geográfica. São Paulo: Perspectiva, 2011 [1952].

FONSECA, Fernanda Padovesi. A inflexibilidade do espaço cartográfico, uma questão para a geografia: análise das discussões sobre o papel da cartografia. Tese (Doutorado em Geografia Física), FFLCH, Universidade de São Paulo, São Paulo, 2004.

GOLDMANN, Lucien. A criação cultural na sociedade moderna. São Paulo: Difel, 1972.

LUCCA, Silvia de. O produto musical nas rádios brasileiras e aspectos de sua influência: um panorama atual paulistano. Dissertação (mestrado em ciências da comunicação) Escola de Comunicação e Artes, Universidade de São Paulo. São Paulo, 2002.

ORTEGA Y GASSET, José. Meditação da técnica. Rio de Janeiro: Livro IberoAmericano, 1963.

RIBEIRO, Ana Clara Torres. Mutações na sociedade brasileira: seletividade em atualizações técnicas da cultura. In SANTOS, Milton; SOUZA, Maria Adélia; SCARLATO, Francisco Capuano \& ARROYO, Monica. O Novo mapa do mundo. São Paulo: Hucitec, 1994. Pp. 151-170.

RIBEIRO, Ana Clara Torres. Pequena reflexão sobre categorias da teoria crítica do espaço: território usado, território praticado. In SOUZA, Maria Adélia de. (et al). Território Brasileiro: usos e abusos. Campinas: Edições Territorial, 2003. Pp. 29-40.

RIBEIRO, Ana Clara Torres. O desenvolvimento local e a arte de 'resolver' a vida. In LIANZA, Sidney \& ADDOR, Felipe. Tecnologia e desenvolvimento social e solidário. Porto Alegre: Editora da UFRGS, 2005. Pp. 109-120.

RIBEIRO, Ana Clara Torres. Territórios da sociedade: por uma cartografia da ação. In: SILVA, Catia Antonia da. Território e ação social: sentidos da apropriação urbana.. Rio de Janeiro: Faperj/Lamparina, 2011. Pp. 19-34.

SÁNCHEZ, Joan-Eugeni. El espacio y la innovacion tecnológica In Espacio, economia y sociedad. Madrid: Siglo XXI-Sintesis, 1992. Pp. 263-319.

SANTOS, Milton e SILVEIRA, María Laura. O Brasil: território e sociedade no início do século XXI. Rio de Janeiro: Record, 2001.

SANTOS, Milton. A formação socioespacial como teoria e como método. Boletim Paulista de Geografia. N 54, 1977. Pp. 81-100.

SANTOS, Milton. Técnica, espaço e tempo. São Paulo-SP: Hucitec, 1994.

SANTOS, Milton. A natureza do espaço: técnica e tempo, razão e emoção. São Paulo-SP: Hucitec, 1997.

SANTOS, Milton. et all. O papel ativo da geografia, um manifesto. Texto apresentado no XII Encontro Nacional de Geógrafos. Florianópolis, 2000. 13 páginas 
Data de Recebimento: 02/06/2015

Data de Aprovação: 08/03/2016 


\section{Para citar essa obra:}

ALVES, C. N. Buscando alternativas cartográficas: uma metodologia de subversão do sistema de informação geográfica. In: RUA [online]. $\mathrm{n}^{\circ}$ 22. Volume 1, p. 107-124 ISSN 1413-2109 - Junho/2016. Consultada no Portal Labeurb - Revista do Laboratório de Estudos Urbanos do Núcleo de Desenvolvimento da Criatividade.

http://www.labeurb.unicamp.br/rua/

Capa: Figura 12. Elaboração do autor.

Laboratório de Estudos Urbanos - LABEURB

Núcleo de Desenvolvimento da Criatividade - NUDECRI

Universidade Estadual de Campinas - UNICAMP

http://www.labeurb.unicamp.br/

\section{Endereço:}

LABEURB - LABORATÓRIO DE ESTUDOS URBANOS

UNICAMP/COCEN / NUDECRI

CAIXA POSTAL 6166

Campinas/SP - Brasil

CEP 13083-892

Fone/ Fax: (19) 3521-7900

Contato: http://www.labeurb.unicamp.br/contato 